Article

\title{
Integrated Life Cycle Energy and Greenhouse Gas Analysis of Exterior Wall Systems for Residential Buildings
}

\section{Reza Broun ${ }^{1, *}$, Hamed Babaizadeh ${ }^{2}$, Abolfazl Zakersalehi ${ }^{1}$ and Gillian F. Menzies ${ }^{3}$}

1 Department of Civil Engineering, University of Texas at Arlington, Arlington, TX 76019, USA; E-Mail: Abolfazl.Zakersalehi@mavs.uta.edu

2 Stantec Consulting Inc., 500 Main Street, Baton Rouge, LA 70801, USA;

E-Mail: Hamed.Babaizadeh@stantec.com

3 Institute for Building and Urban Design, School of the Built Environment, Heriot-Watt University, Edinburgh EH14 4AS, UK; E-Mail: G.Menzies@hw.ac.uk

* Author to whom correspondence should be addressed; E-Mail: R.Broun@gmail.com;

Tel.: +1-617-803-7727.

External Editor: Marc A. Rosen

Received: 23 May 2014; in revised form: 5 November 2014 / Accepted: 6 November 2014 /

Published: 27 November 2014

\begin{abstract}
This paper investigates the breakdown of primary energy use and greenhouse gas (GHG) emissions of two common types of exterior walls in the U.K.: insulated concrete form (ICF) and cavity walls. A comprehensive assessment was conducted to evaluate the environmental performance of each exterior wall system over 50 years of service life in Edinburgh and Bristol. The results indicate that for both wall systems, use phase is the major contributor to the overall environmental impacts, mainly due to associated electricity consumption. For the ICF wall system in Edinburgh, $91 \%$ of GHG emissions were attributed to the use phase, with $7.8 \%$ in the pre-use and $1.2 \%$ in end-of-life phases. For the same system in Bristol, emissions were $89 \%, 9 \%$ and $2 \%$, respectively. A similar trend was observed for cavity wall systems in both locations. It was concluded that in each scenario, the ICF wall system performed better when compared to the cavity wall system. The results of the sensitivity analysis clearly show that the uncertainties relevant to the change of the thickness of the wall are quite tolerable: variable up to $5 \%$, as far as energy and greenhouse emissions are concerned.
\end{abstract}


Keywords: life cycle assessment (LCA); exterior wall system; building envelope; primary energy; greenhouse gas (GHG); residential building

\section{Introduction}

In 2012, the U.K. residential sector consumed nearly $29 \%$ of total primary energy and emitted 158 million tons of $\mathrm{CO}_{2}$ equivalent. It was estimated that $47 \%$ of the life cycle energy use in residential buildings is attributed to the use phase, which is mainly for heating purposes [1]. During the use phase of a typical building, the heat balance significantly determines the overall energy consumption and can constitute up to $80 \%$ of the total life cycle energy. The building envelope has the largest impact on consumed energy in the use phase [2]. Heat exchange between the inner and outer leaf of exterior walls depends on using materials or layers of materials with different thermal conductivity [3]. Replacing traditional exterior walls with more energy efficient walls can reduce the operating energy up to 30\% [4].

To date, the implementation of the cavity wall and insulated concrete form (ICF) has not been yet commercialized at a large scale. Debates exist regarding the life-cycle impacts of the large-scale use of these emerging types of exterior wall systems, especially the impact on primary energy consumption. This study quantitatively examines the breakdown of the primary energy use and GHG emissions of two common types of exterior wall in the U.K., insulated concrete form (ICF) and cavity wall, over the entire lifetime. An analysis of primary energy (both embodied and operational energy) and the associated environmental impacts of a building's exterior wall system can highlight opportunities for reducing primary energy and impacts, leading to the selection of more sustainable building components.

\section{Literature Review}

The first life cycle assessment (LCA) study for the residential sector was published by Raymond and Paul [5] where total life-cycle energy (LCE) in a $4620-\mathrm{m}^{2}$, three-story, typical office building was evaluated for alternative wood, steel and concrete structural systems. The authors estimated the embodied energy, recurring embodied energy associated with maintenance and repair and operating energy for each alternative structural system. They concluded that operating energy is the largest element of the whole life-cycle energy. For two buildings in Vancouver and Toronto with a typical life of 50 years, energy consumed for heating, cooling, ventilation and air conditioning was approximately $80 \%$ and $90 \%$, respectively. However, the embodied energy for the building was approximately equivalent to 4.3, 4.9 and 4.6 years of operating energy for wood, steel and concrete structures. For the colder climate in Toronto, the number of equivalent years reduced to 2.6, 2.9 and 2.7 years, respectively. Adalberth [6] presented a method to compute energy consumption during the life cycle of a building and evaluated all temporal phases of the building's lifespan, from the point where construction materials were extracted through when the building was demolished. Subsequently, Adalberth [7] studied the life cycle energy consumption of three prefabricated single-unit dwellings in Sweden and concluded that almost $85 \%$ of the total energy consumption is used within the use phase. Thormark [8] assessed low energy buildings in Sweden. The results illustrated that embodied energy makes up a considerable part (up to 40\%) of the total energy consumption in these buildings, and recycling plays a significant role in reducing the 
embodied energy from using reusable/recyclable materials by about $37 \%$ to $42 \%$. Since then, a number of LCA studies have been performed to assess environmental impacts associated with the residential sector [9-13].

Several studies have investigated the effect of the change of envelope materials on the operating energy and environmental performances of buildings. Monteiro and Freire [14] conducted LCA of a single family house with seven alternative exterior walls. The house was evaluated using two life cycle impact assessments (LCIA) methods: CML 2001 (Chain Management of Leiden University) that is a problem oriented method; and Eco-indicator (EI) 99 (damage oriented). The results showed that in CML2001, heating is the most significant process in eight out of ten impact categories, other than ozone layer depletion and fresh water ecotoxicity. The authors concluded that lightweight concrete blocks, wood frame and cladding and hollow brick masonry and exterior wood cladding have a significantly lower impact for global warming potential (GWP), acidification and eutrophication categories. For the EI'99, similar results as the CML approach can be observed. The comparison of CML and EI'99 normalized results illustrates that the most significant categories for EI'99 are fossil fuels and respiratory inorganics, whereas marine ecotoxicity and abiotic depletion are the largest share of environmental categories for CML 2001. Kahhat et al. [15] executed LCA over a single-story residential building in the United States with different exterior wall systems considering multiple environmental indicators: air pollution index, energy consumption, GWP, resource use (e.g., water, oil, etc.), solid waste emissions and a water pollution index within a 50-year lifespan. The results revealed that insulated concrete wall had the least environmental indicators in terms of primary energy consumption and solid waste generation, air pollution index, water pollution index and GWP, followed by concrete blocks and steel studs. Although, traditional wood frames contributed to the smallest extent of primary energy consumption and GWP among all others alternatives when accounting for the pre-use phase only. Azari [16] studied six types of building envelopes considering the change of insulation and glazing along with the envelope's wall-to-window ratio (WWR) to identify the scenario with the least environmental impacts. The results revealed that the lowest environmental impacts in all categories of interest, except smog formation, happens by the use of scenario $2(40 \%$ WWR, mineral wool insulation, fiberglass-framed argon-filled low-e DG) followed by scenario $3(60 \% \mathrm{WWR}$, fiberglass batt insulation, fiberglass-framed air-filled low-e DG). On the other hand, Scenario $6(80 \%$ WWR, mineral wool insulation and aluminum-framed argon-filled low-e DG) represents the highest environmental impacts in most categories, including operating energy use, acidification, eutrophication and ozone depletion categories, which also contributes as the second highest scenario for fossil fuel consumption and GWP.

In the U.K., some authors studied LCA in the residential sector. Broun and Menzies [17] analyzed three types of partition wall systems: brick from clay, hollow blocks from concrete and traditional timber frames. They observed that a clay brick wall poses the most significant environmental impacts in terms of GWP and acidification potential, accounting for $58 \mathrm{~kg} \mathrm{CO}_{2}$ equivalent and $1.3 \mathrm{~kg} \mathrm{SO} 2$ equivalent, respectively, over the entire life cycle. In a well-rounded LCA study, Cuéllar-Franca and Azapagic [18] compared the three most common types of house in the U.K.: detached; semi-detached; and terraced. The results showed that GWP over the 50-year lifespan of the detached house is $455 \mathrm{t}$ of $\mathrm{CO}_{2}$ equivalent, $374 \mathrm{t} \mathrm{CO}_{2}$ equivalent for the semi-detached and $309 \mathrm{t} \mathrm{CO}_{2}$ equivalent for the terraced house. It was found that the use phase (especially space heating and water heating) had the largest contribution to the majority of environmental impacts. They also concluded that about $90 \%$ of the GWP is from the use 
phase, $9 \%$ from the construction (embodied carbon) phase and 1\% from end-of-life waste management. Similar trends are perceived for most environmental impacts, e.g., acidification potential, ozone depletion potential.

Ip and Miller [19] performed a comprehensive LCA on energy-efficient alternative building materials in the U.K., where they concluded that $1 \mathrm{~m}^{2}$ of hemp-lime wall can sequestrate $82.71 \mathrm{~kg}$ of $\mathrm{CO}_{2}$, which leads to a compensation of $46.43 \mathrm{~kg} \mathrm{CO}_{2}$ of $\mathrm{GHG}$ emitted within the pre-use phase and storage of $36.08 \mathrm{~kg}$ of $\mathrm{CO}_{2}$ equivalent.

The review of the literature in the field shows that there is a potential to investigate energy performance and GHG emissions of the emerging building envelopes. On the other hand, the majority of current building envelopes are not energy efficient, while play a key role in increasing the environmental burdens in the use phase [18]. Therefore, since very few studies have been conducted on the exterior wall systems in the U.K., this study fills the gap and compares the ICF wall system and the cavity wall system from an LCA perspective in terms of greenhouse gas and energy performance.

\section{Methodology}

The reference building is a semi-detached house with single family occupancy located in Edinburgh and Bristol, in the U.K., with $100 \mathrm{~m}^{2}$ of living area and a service life of 50 years. The alternative exterior wall systems used for this building are ICF and cavity wall to analyze the energy performance and greenhouse gas emissions. The functional unit was considered as $1 \mathrm{~m}^{2}$ of each exterior wall system, and all of the emissions, resources and energy consumption are expressed as "per square meter of wall". Figure 1, represents the schematic drawings of two exterior wall systems for this study.

Figure 1. Exterior wall scenarios with section details. (a) Cavity wall system; (b) ICF wall system.

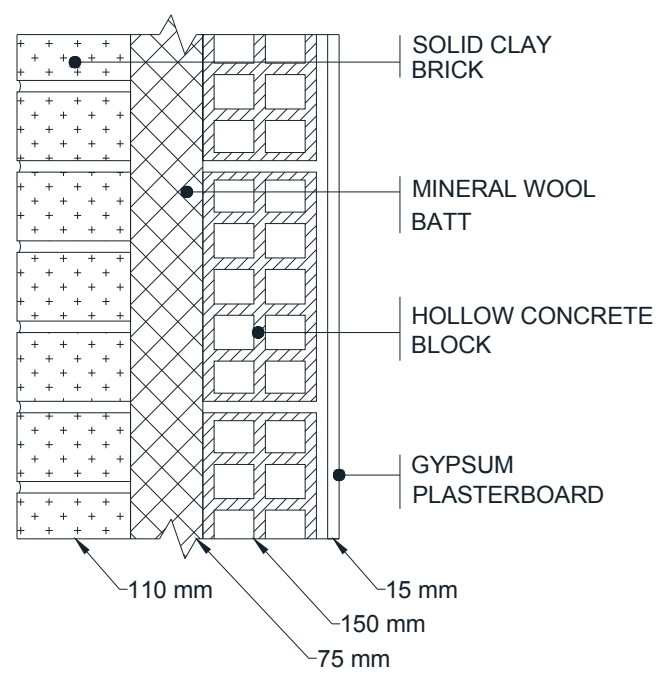

(a)

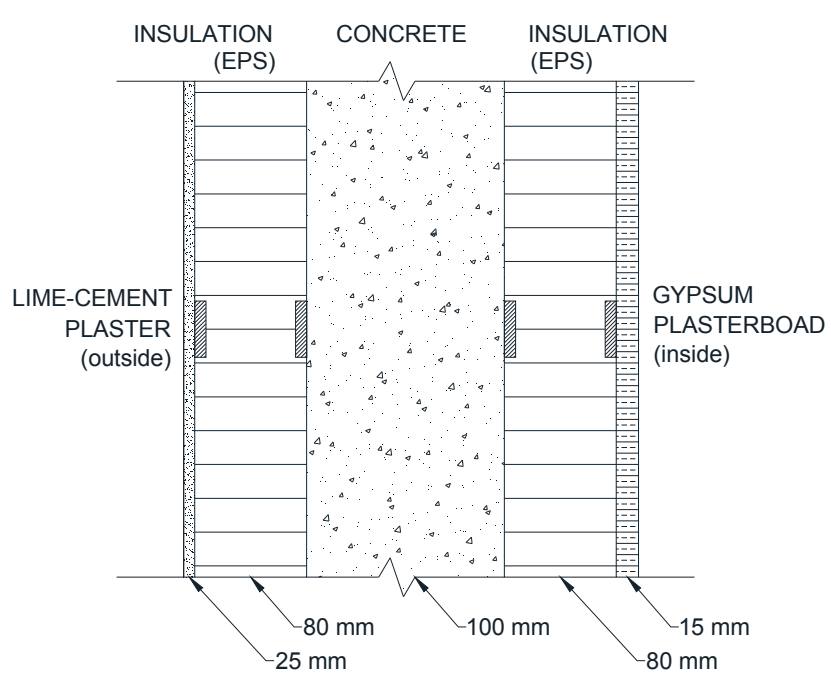

(b)

The selected ICF wall system was composed of a 100-mm layer of reinforced concrete sandwiched between two 80-mm layers of expanded polystyrene insulation. The cavity wall system consists of two "skins" separated by a hollow space (cavity). The skins are commonly masonry material, such as brick and concrete blocks. The cavity wall considered here has the following layers from outside to the inside: clay brick, 110-mm thick; mineral wool batt with a thickness of $40 \mathrm{~mm}$; concrete blocks, 150 -mm thick; 
and gypsum board, 15-mm thick on the innermost side. The details of the components of each type of exterior wall are listed in Tables 1 and 2.

Table 1. Description of the components of the insulated concrete form (ICF) wall system.

\begin{tabular}{lcccc}
\hline \multicolumn{1}{c}{ Components } & $\begin{array}{c}\text { Thickness } \\
(\mathbf{m m})\end{array}$ & $\begin{array}{c}\text { Thermal Conductivity } \\
(\mathbf{W} / \mathbf{m} \cdot \mathbf{K})\end{array}$ & $\begin{array}{c}\text { Density } \\
\left(\mathbf{k g} / \mathbf{m}^{\mathbf{3}}\right)\end{array}$ & $\begin{array}{c}\text { Weight } \\
\left(\mathbf{k g} / \mathbf{m}^{\mathbf{2}}\right)\end{array}$ \\
\hline $\begin{array}{l}\text { lime-cement plaster } \\
\begin{array}{l}\text { outer insulation } \\
\text { (expanded polystyrene) }\end{array}\end{array}$ & 25 & 0.90 & 1800 & 45 \\
$\begin{array}{l}\text { concrete } \\
\text { inner insulation }\end{array}$ & 100 & 0.035 & 25 & 2 \\
$\begin{array}{l}\text { (expanded polystyrene) } \\
\text { gypsum plasterboard }\end{array}$ & 80 & 1.4 & 2350 & 235 \\
\hline Total & 15 & 0.035 & 25 & 2 \\
\hline
\end{tabular}

Table 2. Description of the components of the cavity wall system.

\begin{tabular}{lcccc}
\hline Components & $\begin{array}{c}\text { Thickness } \\
(\mathbf{m m})\end{array}$ & $\begin{array}{c}\text { Thermal Conductivity } \\
(\mathbf{W} / \mathbf{m} \cdot \mathbf{K})\end{array}$ & $\begin{array}{c}\text { Density } \\
\left(\mathbf{k g} / \mathbf{m}^{\mathbf{3}}\right)\end{array}$ & $\begin{array}{c}\text { Weight } \\
\left(\mathbf{k g} / \mathbf{m}^{\mathbf{2}}\right)\end{array}$ \\
\hline gypsum plasterboard & 15 & 0.70 & 1400 & 21 \\
hollow concrete block & 150 & 0.63 & 1200 & 18 \\
mineral wool batt & 75 & 0.030 & 40 & 3 \\
solid clay brick & 110 & 0.8 & 2000 & 220 \\
\hline Total & 350 & $U$-value $\left(\mathrm{W} / \mathrm{m}^{2} \cdot \mathrm{K}\right)=0.34$ & - & 262 \\
\hline
\end{tabular}

\subsection{System Boundary}

The system boundary was defined as the point of the manufacturing of individual components of each exterior wall followed by the transportation of individual components to the site of construction. The assembly of wall units, the use and disposal of wall components were also considered. The system boundary includes all activities undertaken in each phase. It was assumed that all identical life cycle stages are excluded to simplify the system boundary. The following sections provide an overview of the assumptions made for each type of case study exterior wall.

\subsection{Pre-Use Phase}

For the pre-use phase, the quantities of material for the construction of each type of exterior wall are calculated using expert consultations and construction guides and specification [10]; then, primary energy requirements and GHG emissions were calculated using SimaPro 8 software based on the Ecoinvent 3 database [20]. The steps required to determine the inventory of energy and carbon include the formulation of a data collection plan, actual data collection and evaluation and reporting of the results. In this study, data were collected from Ecoinvent 3, as well as several other sources (i.e., technical reports, publications, discussion with consultants in the field of building materials and the literature). Where U.K.-specific inventory data were not available, data were used from other databases, such as the Inventory of Carbon and Energy (ICE) version 2.0, which have been adjusted to reflect U.K. conditions 
with respect to U.K. energy grid. For having an accurate comparative analysis, U.K. data corresponding to average technologies not older than 10 years were utilized. The ICE lists embodied energy (energy consumed during extraction of raw materials, production of building materials and transportation to construction site) carbon and GHG emissions for a large number of building materials. The current paper addresses GHG intensity on a 100-year time horizon, which is the relevant metric for climate change.

In terms of exterior wall installation, once materials are delivered to construction site, some mechanical tools are needed to assemble the components of the exterior wall systems. For each wall system, inventories of constituent layers were aggregated based on component weights for the functional unit $\left(1 \mathrm{~m}^{2}\right)$ of each exterior wall system. The cavity wall system required no additional inputs, because, in most cases, the walls themselves are assembled using human labor. For the ICF wall system, however, additional energy input is required due to electricity needed to pour and vibrate the concrete. Emissions associated with this input were automatically evaluated by SimaPro 8 software [20].

\subsection{Use Phase}

The use phase represents the household energy demand which mostly includes electricity and natural gas. Autodesk Ecotect 2011 [21] was used to simulate the total energy consumption of the building per year based on the ratio between residential electricity and natural gas consumption from the 2012 U.K. power generation mix. Maintenance activities considered in the use phase involve repairing and replacing exterior walls. According to Silvestre et al. [22] and Bastos et al. [23], maintenance activities (including, e.g., replacement of coatings) can represent up to $20 \%$ of the life cycle energy and GHG emissions. The primary energy and GHG emissions associated with these maintenance phases were based on ICE version 2.0. The inventory for this phase was comprised entirely of electricity consumption values corresponding to the building's HVAC demands, which varies from location to location. In order to obtain these values, Ecotect 2011 software was used to model a $100-\mathrm{m}^{2}$ semi-detached house, which is representative of $60 \%$ of the residential buildings in the U.K. The zoning pattern was assigned 1 per floor, and the floor to ceiling height was set as $2.8 \mathrm{~m}$. A single east-facing door and two double windows were added to dwelling specifications. Default dimensions were set by the software (doors, $2 \mathrm{~m} \times 0.9 \mathrm{~m}$; and windows, $1.5 \mathrm{~m} \times 1.3 \mathrm{~m}$ ). Based on the location, average values for electricity consumption were calculated and illustrated in Table 3.

Table 3. The annual average of energy consumption for case study building during the use phase.

\begin{tabular}{cccc}
\hline $\begin{array}{c}\text { Mean Electricity Consumption } \\
\text { (Cavity Walls, } \text { MWh) }\end{array}$ & \multicolumn{2}{c}{$\begin{array}{r}\text { Mean Electricity Consumption } \\
\text { (ICF Walls, MWh) }\end{array}$} \\
\hline Edinburgh & Bristol & Edinburgh & Bristol \\
13.9 & 11.8 & 11.6 & 9.7 \\
\hline
\end{tabular}

\subsection{End of Life Phase}

In this phase, multiple options were considered based on current construction waste management strategies in U.K. and Europe. Recycling, incineration and landfilling were picked out as potential strategies for demolition waste management. Exterior walls were disassembled into their individual components. After a 50-year life cycle, various treatment methods were allocated for each component 
and detailed in specific waste scenarios. Landfilling was the dominant waste treatment mechanism. The allocation for each material is provided in Table 4.

Table 4. The allocation for each component at the end of life phase.

\begin{tabular}{lccc}
\hline \multicolumn{1}{c}{ Component } & Incineration & Landfill & Recycling \\
\hline solid clay brick (cavity wall) & - & $50 \%$ & $50 \%$ \\
hollow concrete block (cavity wall) & - & - & $100 \%$ \\
mineral wool batt (ICF wall) & - & $100 \%$ & - \\
gypsum plasterboard (ICF wall and Cavity wall) & - & $100 \%$ & - \\
concrete (ICF wall) & - & $100 \%$ & - \\
expanded polystyrene (ICF wall) & $50 \%$ & $50 \%$ & - \\
\hline
\end{tabular}

\section{Results and Discussions}

Table 5 presents the GHG emissions of the use phase for both types of exterior wall systems. In absolute terms, the ICF wall system is associated with the lowest energy demand and GHG emissions; the cavity wall system has $10 \%$ and $12 \%$ higher GHG emissions for Edinburgh and Bristol, respectively. Total GHG emissions during the use phase over the lifespan of the ICF wall system and cavity wall system in Edinburgh is 1261 and $1392 \mathrm{~kg} \mathrm{CO} 2$ equivalent, respectively. For Bristol, a similar trend is observed on a per square meter basis, primarily due to different climatic conditions, which leads to 1059 and $1184 \mathrm{~kg} \mathrm{CO}_{2}$ equivalent for the cavity wall system.

Table 5. GHG emissions for each square meter of the exterior wall system during the use phase for the entire life cycle $\left(\mathrm{kg} \mathrm{CO}_{2}\right.$ equivalent).

\begin{tabular}{ccc}
\hline Location & ICF Wall System & Cavity Wall System \\
\hline Edinburgh & 1261 & 1392 \\
Bristol & 1059 & 1184 \\
\hline
\end{tabular}

Total life cycle analysis results, considering all phases simultaneously, are shown in Figure 2. It articulates that in both locations, the ICF wall system has the most GHG emissions in terms of $\mathrm{CO}_{2}$ equivalent. Based on the obtained results from both locations, it was concluded that the cavity wall has comparatively lower GHG emissions and is less environment-friendly. Due to more severe Scottish climates, Edinburgh has higher energy consumption amount during the use phase. The breakdown of the total GHG emitted to the environment for each location over the life cycle is shown in Tables 6 and 7.

Table 6. ICF wall system: GHG emissions for the entire life cycle ( $\mathrm{kg} \mathrm{CO}_{2}$ equivalent).

\begin{tabular}{ccccc}
\hline Location & Pre-Use Phase & Use Phase & End of Life Phase & Total $\mathbf{C O}_{2}$ Equivalent \\
\hline Edinburgh & 109.4 & 1261 & 17.2 & 1387.6 \\
Bristol & 107 & 1059 & 17.8 & 1183.8 \\
\hline
\end{tabular}

Table 7. Cavity Wall system: GHG emissions for the entire life cycle ( $\mathrm{kg} \mathrm{CO}_{2}$ equivalent).

\begin{tabular}{ccccc}
\hline Location & Pre-Use Phase & Use Phase & End of Life Phase & Total $\mathbf{C O}_{2}$ Equivalent \\
\hline Edinburgh & 161.3 & 1392 & 11.1 & 1564.4 \\
Bristol & 159.4 & 1184 & 11.9 & 1355.3 \\
\hline
\end{tabular}


Figure 2. Greenhouse gas emissions in $\mathrm{kg} \mathrm{CO}_{2}$ equivalent for the entire life cycle per functional unit.

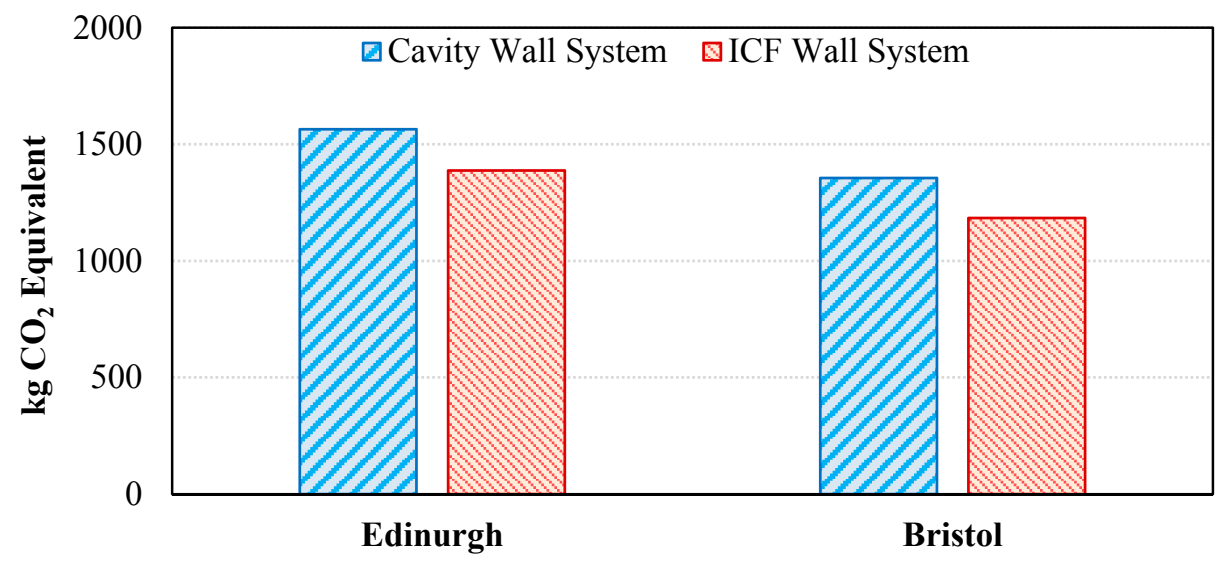

Figures 3 and 4 show a breakdown of GHG emissions by each phase of the life cycle of exterior wall systems for each location. For the ICF wall system in Edinburgh, the use phase contributes to $91 \%$ of GHG emissions, followed by the pre-use phase (7.8\%) and the end-of-life phase (1.2\%). For Bristol, the contribution of each phase is $89 \%, 9 \%$ and $2 \%$, respectively. Approximately the same trend is found for cavity wall systems in Edinburgh and Bristol.

Figure 3. Breakdown of GHG emissions for the cavity wall system over the entire life cycle.

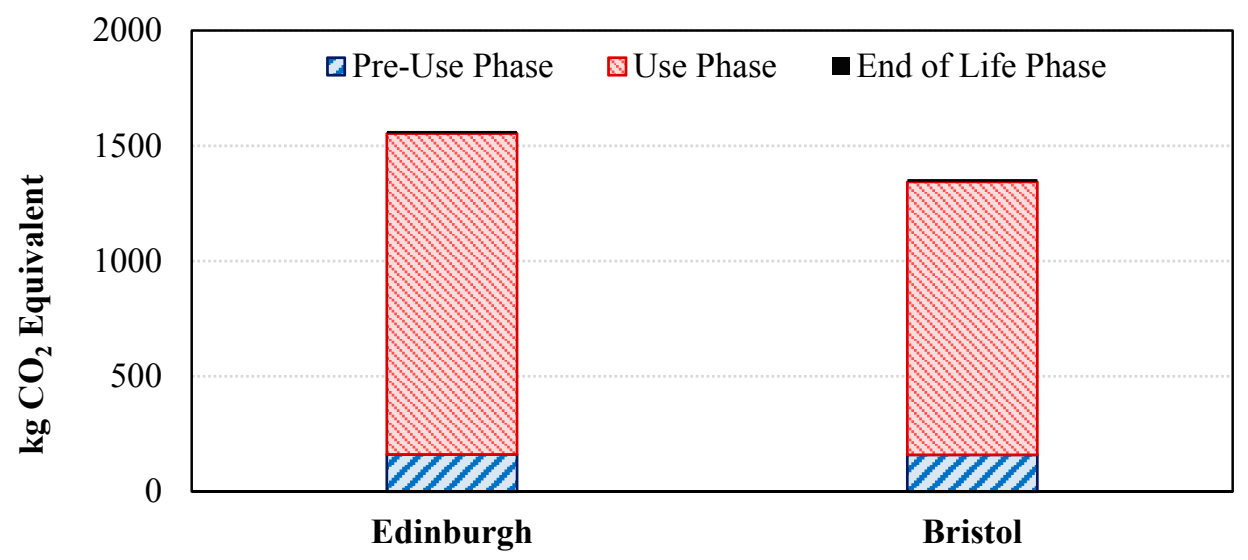

Figure 4. Breakdown of GHG emissions for the ICF wall system over the entire life cycle.

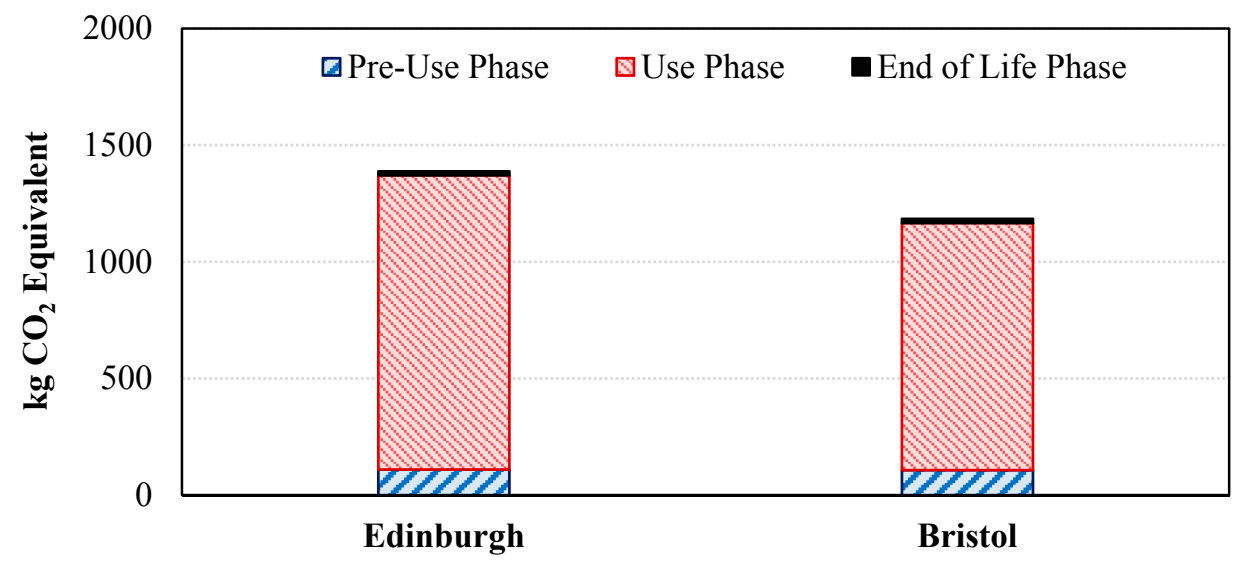




\section{Sensitivity Analysis}

Sensitivity analysis is important at each phase. Conducting a sensitivity analysis could assist stakeholders to decide which material has the most influence on the environmental performance of an exterior wall system. Therefore, in order to assess the reliability and representativeness of the results, a sensitivity analysis was carried out through variation in inputs by changing the thickness of the existing wall components to find out the impact on the results, since constructing a lightweight exterior wall is favored by most construction contractors.

Thus, sensitivity analysis was done by changing the thickness of the wall components as follows:

(1) The brick thickness of the cavity wall was decreased to $50 \mathrm{~mm}$ from the original $110-\mathrm{mm}$ thickness to increase the heat transfer coefficient within the wall with the new $U$-value of $0.38 \mathrm{~W} / \mathrm{m}^{2} \cdot \mathrm{K}$ (Cavity-TK).

(2) For ICF wall system, thickness of the reinforced concrete material was decreased to $50 \mathrm{~mm}$ from the original $100 \mathrm{~mm}$ with the new U-value of $0.23 \mathrm{~W} / \mathrm{m}^{2} \cdot \mathrm{K}(\mathrm{ICF}-\mathrm{TK})$. New data from each component of the exterior wall system were inputted in SimaPro 8 and Ecotect 2011 during the pre-use phase, use phase and end of life phase. Final results have been tabulated and represented using bar charts, as shown in Figures 5 and 6, where the left side of the red dashed line is related to the exterior wall system with a reduced thickness.

Figure 5. Sensitivity analysis for the cavity wall system in $\mathrm{kg} \mathrm{CO}_{2}$ equivalent.

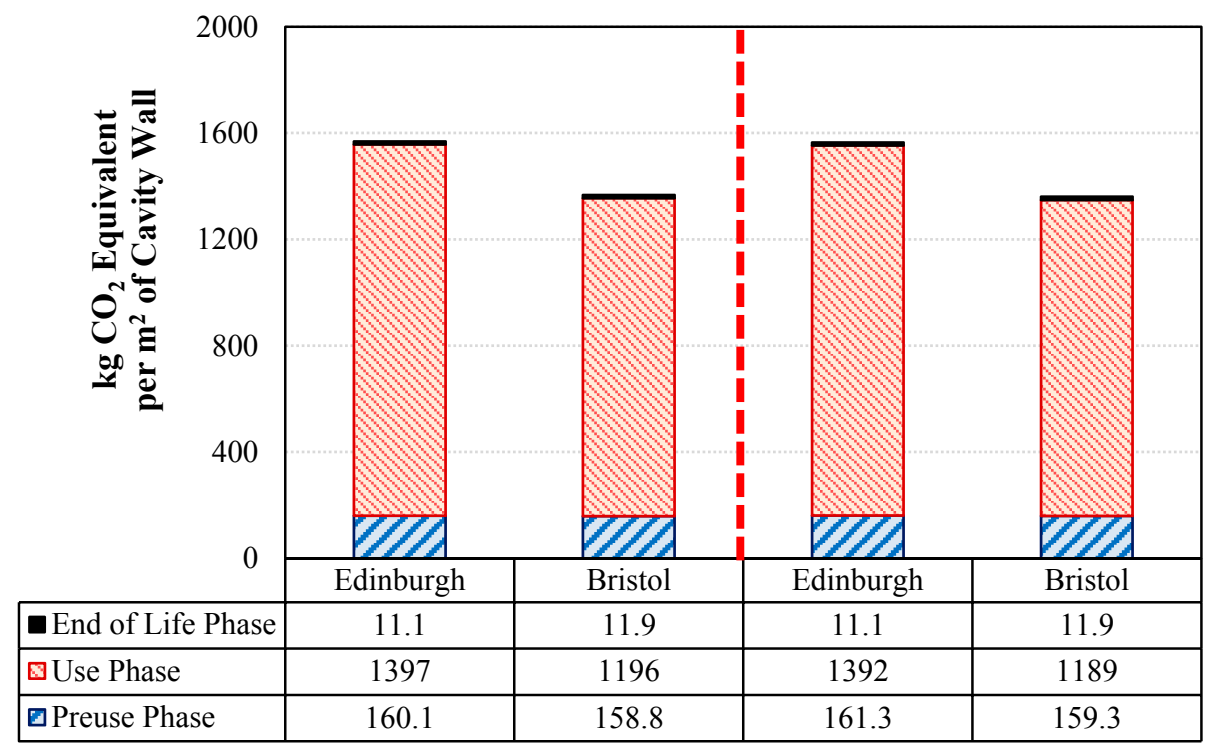


Figure 6. Sensitivity analysis for the ICF wall system in $\mathrm{kg} \mathrm{CO}_{2}$ equivalent.

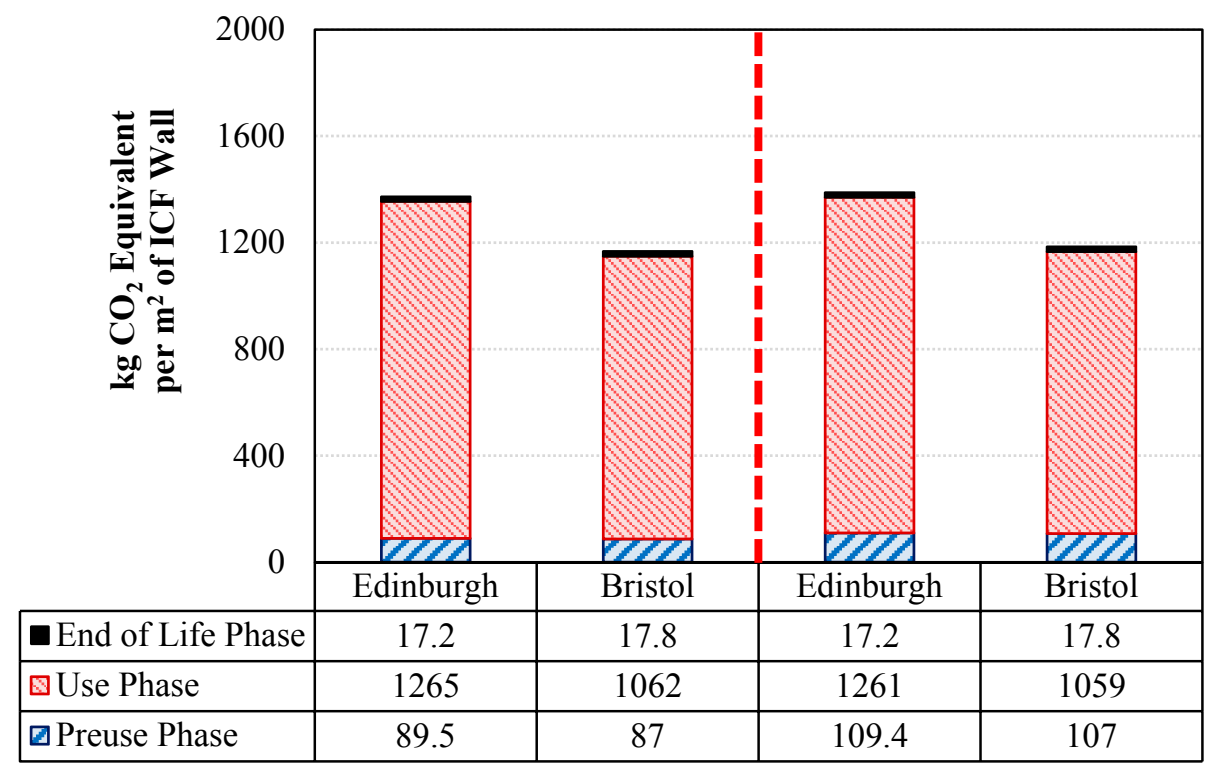

The GHG emissions relevant to the pre-use phase, use phase and end of life phase were re-calculated by considering different thicknesses of the exterior wall. The baseline LCA model was then compared to the second model in which the thickness was decreased. As can be seen in Figures 5 and 6 , the differences in terms of GHG emissions are lower than 5\%, in comparison with the baseline model, and virtually lead to the same results. The results of the sensitivity analysis clearly show that the uncertainties relevant to the change of the thickness of the wall are quite tolerable, as far as energy and greenhouse emissions are concerned. This is because during the use phase, more electricity is consumed to heat the building. A building in more southerly latitudes with warmer weather (i.e., Bristol) demonstrates less sensitivity, due to lower temperature fluctuations.

\section{Conclusions}

During the above comparative analysis of two different exterior wall systems, the manufacturing phase, use phase and end-of-life phase have been assessed from energy consumption and GHG emissions perspectives. A sensitivity analysis has been conducted to find the effect of the change in inputs on the inventory vector. The results indicate that the use phase is also the main contributor to all other environmental impacts, which are mainly related to energy use, because electricity consumption is a major contributor to the impacts associated with both options. The use phase contributes $91 \%$ of GHG emissions, followed by the pre-use phase (7.8\%) and the end-of-life phase (1.2\%) for an ICF wall system in Edinburgh. The contribution of each phase for Bristol is $89 \%, 9 \%$ and $2 \%$, respectively. A similar trend is found for the cavity wall system in Edinburgh and Bristol. It is clear that in each scenario, the ICF wall system has superior performance when compared to the cavity wall system. It can be concluded that with respect to emissions, ICF walls are a better option than cavity walls. For colder climates, ICF walls perform better with respect to insulation, and hence, greater savings in energy are realized. However, if there are other innovative materials with superior performance, further studies should be conducted to compare the efficiency. Results of sensitivity analysis clearly show that the uncertainties 
relevant to the change of the thickness of wall are quite tolerable, as far as energy and greenhouse emissions are concerned.

In order to optimize the thickness and material properties, a separate analysis is necessary. This was considered to be beyond the scope of this analysis. This study would benefit from contextualized research, considering both the full building construction and the activities of its occupants. However, the comparative nature of this study and its methodological implications (simplification of the systems by the exclusion of identical life cycle stages and system boundaries) should not be forgotten. Using life cycle analysis results out of context can lead to incorrect conclusions.

\section{Author Contributions}

Reza Broun and Gillian F. Menzies designed the research; Reza Broun, Abolfazl Zakersalehi and Hamed Babaizadeh performed the research; Reza Broun, Hamed Babaizadeh and Abolfazl Zakersalehi analyzed the data; and Reza Broun, Hamed Babaizadeh and Gillian F. Menzies wrote the paper. All authors have read and approved the final manuscript.

\section{Conflicts of Interest}

The authors declare no conflict of interest.

\section{References}

1. ECUK (Engineering Council UK). Chapter 1: Overall Energy Consumption in the UK. In Energy Consumption in the UK; Department of Energy \& Climate Change: London, UK, 2013.

2. Ramesh, T.; Prakash, R.; Shukla, K.K. Life cycle energy analysis of a residential building with different envelopes and climates in Indian context. Appl. Energy 2012, 89, 193-202.

3. Yohanis, Y.G.; Norton, B. Life-cycle operational and embodied energy for a generic single-storey office building in the UK. Energy 2002, 27, 77-92.

4. Sharma, A.; Shree, V.; Nautiyal, H. Life cycle environmental assessment of an educational building in Northern India: A case study. Sustain. Cities Soc. 2012, 38, 22-28.

5. Cole, R.J.; Kernan, P.C. Life-cycle energy use in office buildings. Build. Environ. 1996, 31, 307-317.

6. Adalberth, K. Energy use during the life cycle of buildings: A method. Build. Environ. 1997, 32, 317-320.

7. Adalberth, K. Energy use during the life cycle of single-unit dwellings: Examples. Build. Environ. 1997, 32, 321-329.

8. Thormark, C. A low energy building in a life cycle-Its embodied energy, energy need for operation and recycling potential. Build. Environ. 2002, 37, 429-435.

9. Arena, A.P.; de Rosa, C. Life cycle assessment of energy and environmental implications of the implementation of conservation technologies in school buildings in Mendoza-Argentina. Build. Environ. 2003, 38, 359-368.

10. Blengini, G.A. Life cycle of buildings, demolition and recycling potential: A case study in Turin, Italy. Build. Environ. 2009, 44, 319-330.

11. Peuportier, B.L.P. Life cycle assessment applied to the comparative evaluation of single family houses in the French context. Energy Build. 2001, 33, 443-450. 
12. Utama, A.; Gheewala, S.H. Life cycle energy of single landed houses in Indonesia. Energy Build. 2008, 40, 1911-1916.

13. Babaizadeh, H.; Hassan, M. Life cycle assessment of nano-sized titanium dioxide coating on residential windows. Constr. Build. Mater. 2013, 40, 314-321.

14. Monteiro, H.; Freire, F. Life-cycle assessment of a house with alternative exterior walls: Comparison of three impact assessment methods. Energy Build. 2012, 47, 572-583.

15. Kahhat, R.; Crittenden, J.; Sharif, F.; Fonseca, E.; Li, K.; Sawhney, A.; Zhang, P. Environmental impacts over the life cycle of residential buildings using different exterior wall systems. J. Infrastruct. Syst. 2009, 15, 211-221.

16. Azari, R. Integrated energy and environmental life cycle assessment of office building envelopes. Build. Environ. 2014, 82, 156-162.

17. Broun, R.; Menzies, G.F. Life cycle energy and environmental analysis of partition wall systems in the UK. Procedia Eng. 2011, 21, 864-873.

18. Cuéllar-Franca, R.M.; Azapagic, A. Environmental impacts of the UK residential sector: Life cycle assessment of houses. Build. Environ. 2012, 54, 86-99.

19. Ip, K.; Miller, A. Life cycle greenhouse gas emissions of hemp-lime wall constructions in the UK. Resourc. Conserv. Recycl. 2012, 69, 1-9.

20. Pré Consultants. Available online: http://www.pre.nl/ (accessed on 12 November 2013).

21. Ecotect energy Analysis. EcoTect Energy Simulation Software, version 2011; Atodesk: San Rafael, CA, USA, 2011.

22. Silvestre, J.D.; de Brito, J.; Pinheiro, M.D. From the new European Standards to an environmental, energy and economic assessment of building assemblies from cradle-to-cradle (3E-C2C). Energy Build. 2013, 64, 199-208.

23. Bastos, J.; Batterman, S.A.; Freire, F. Life-cycle energy and greenhouse gas analysis of three building types in a residential area in Lisbon. Energy Build. 2014, 69, 344-353.

(C) 2014 by the authors; licensee MDPI, Basel, Switzerland. This article is an open access article distributed under the terms and conditions of the Creative Commons Attribution license (http://creativecommons.org/licenses/by/4.0/). 